\title{
Nanofiltration and reverse osmosis as a platform for production of natural botanic extracts: The case study of carob by-products
}

\author{
Mohammad Almanasrah ${ }^{\mathrm{a}, 1}$, Carla Brazinha ${ }^{\mathrm{a}, *}$, Mari Kallioinen ${ }^{\mathrm{b}}$, Luís C. Duarte ${ }^{\mathrm{c}}$, Luísa B. Roseiro ${ }^{\mathrm{c}}$, \\ Rafal Bogel-Lukasik ${ }^{c}$, Florbela Carvalheiro ${ }^{c}$, Mika Mänttäri ${ }^{b}$, João G. Crespo ${ }^{a}$ \\ a LAQV, REQUIMTE, Departamento de Química, Faculdade de Ciências e Tecnologia, Universidade Nova de Lisboa, 2829-516 Caparica, Portugal \\ ${ }^{\mathrm{b}}$ Laboratory of Membrane Technology and Technical Polymer Chemistry, Department of Chemical Technology, Lappeenranta University of Technology, P.O. Box 20, Lappeenranta \\ FIN 53851, Finland \\ ${ }^{c}$ Laboratório Nacional de Energia e Geologia - Unidade de Bioenergia (LNEG-UB), Edifício K2, Estrada do Paço do Lumiar, 22, 1649-038 Lisboa, Portugal
}

\section{A R T I C L E I N F O}

\section{Article history:}

Received 21 April 2015

Received in revised form 6 June 2015

Accepted 9 June 2015

Available online 10 June 2015

\section{Keywords:}

Nanofiltration

Diafiltration

Carob

Phenolic compounds

Natural extract

\begin{abstract}
A B S T R A C T
Carob kibbles are a low-cost and renewable source of economically relevant phenolic compounds (high value catechin and its derivatives and gallic acid) and abundant in small sugars. This work aims at producing two distinct natural extracts from carob kibbles, one extract enriched in catechin and its derivatives for the nutraceuticals market and an extract enriched in sugars for the food industry. This valorisation strategy involves an integrated process based on membrane technology that fulfils the zero discharge principle and may be applied to other agro-industrial by-products. Different aqueous extraction schemes were considered (a one-step process and a two-steps approach). The aqueous extracts obtained were fractionated by diananofiltration and the fractions obtained were evaluated in terms of their content in target products. An integrated scheme for production of fractionated extracts is proposed based on the experimental work developed assuring, simultaneously, a minimal use of resources and emission of waste.
\end{abstract}

(C) 2015 Published by Elsevier B.V.

\section{Introduction}

Carob by-products from the carob seed gum industry (carob kibbles), have a high content in marketable sugars and phenolic compounds, but are currently only used in low value applications such as animal feed and regional confectionary. The development of a valorisation strategy for carob kibbles should take into consideration these two classes of compounds. Besides the high concentration of mono- and disaccharides (glucose, fructose and sucrose), several studies reported that carob kibbles have a high variety of antioxidant phenolic compounds comparable to olive residues [1]. According to Avallone et al. [2] and Corsi et al. [3], water extractable carob phenolic compounds are mainly gallic acid and also (-)-catechin and its derivatives: (-)-epigallocatechin,

Abbreviations: $c_{i}$, concentration of compound $i ; D$, number of diafiltration volumes; GAE, gallic acid equivalents; $J_{v}$, volumetric flux; $L_{p}$, permeability; MWCO, molecular weight cut-off; NF, nanofiltration; $p$, pressure; $R_{i}$, apparent rejection of compound $i$; RO, reverse osmosis; VRF, volume reduction factor; $V_{w}$, volume of solvent added to the retentate; subscript perm, permeate.

* Corresponding author.

E-mail address: c.brazinha@fct.unl.pt (C. Brazinha).

1 Permanent address: Laboratory of Membrane Technology and Technical Polymer Chemistry, Department of Chemical Technology, Lappeenranta University of Technology, P.O. Box 20, Lappeenranta FIN 53851, Finland. (-)-epicatechin gallate, and (-)-epigallocatechin gallate, also present in green tea. Furthermore, carob derived phenolic compounds have also been shown to present anti-tumural activities [4,5].

The valorisation strategy of carob kibbles should involve an effective separation between (more valuable) phenolic compounds and sugars, increasing the economic value of their crude extracts. The production of an extract from carob kibbles enriched in catechins and its derivatives is very attractive for the profitable nutraceuticals market. Additionally, the production of a natural extract enriched in mono- and disaccharides has also economical interest to the food industry in general. Nevertheless, this fractionation is a demanding task because sugars are much more abundant than phenolic compounds in carob kibbles extracts and the target compounds have similar molecular mass.

The release and recovery of phenolic compounds from carob kibbles was carried out by extraction with water, a common biocompatible solvent $[3,6]$. In our previous work [7], a one-step aqueous extraction from carob kibbles was optimised aiming the recovery of phenolic compounds. However, the extract obtained presented a high concentration in mono- and disaccharides and gallic acid. Therefore, a sequential two-step extraction process was developed in order to obtain two different fractions: a first extract enriched in sugars and gallic acid with a reduced concentration in phenolic 